\title{
Radar Signatures of Sahelian Surfaces in Mali Using ENVISAT-ASAR Data
}

\author{
Frédéric Baup, Eric Mougin, Pierre Hiernaux, Armand Lopes, Patricia De Rosnay, and Isabelle Chênerie
}

\begin{abstract}
This paper presents an analysis of ENSIVAT Advanced Synthetic Aperture Radar data acquired over a Sahelian region located in Mali, West Africa. The considered period is 2004-2005 and includes two rainy seasons. Emphasis is put on two ScanSAR modes, namely, the Global Monitoring (GM) and the Wide Swath (WS) modes characterized by spatial resolutions of about $1 \mathrm{~km}$ and $150 \mathrm{~m}$, respectively. Results show that the WS mode offers better performance in terms of radiometric resolution, radiometric stability, and speckle reduction than the GM mode. The latter is more appropriate for studies at large scale $(>10 \times 10 \mathrm{~km})$. In both modes, pronounced angular and temporal signatures are observed for most soil surfaces, and azimuthal effects are observed on markedly orientated rocky surfaces. In contrast, polarization differences (VV/HH) are small during the dry season except on flat loamy soil surfaces. Finally, a relationship is observed between the normalized WS backscattering signal at HH polarization and the surface soil moisture of sandy soils.
\end{abstract}

Index Terms-Advanced Synthetic Aperture Radar (ASAR), ENVISAT, global monitoring, radar, sahel, soil moisture, wide swath.

\section{INTRODUCTION}

$\mathbf{S}$ EVERAL years of active microwave C-band observations have been available over the Sahel since July 1991 with the launching of the European Remote Sensing (ERS) satellite ERS-1, followed by ERS-2 in 1995, by RADARSAT in 1995, and by the Advanced Synthetic Aperture Radar (ASAR) onboard ENVISAT in 2002. Among them, the ERS platforms carry two types of active microwave instruments that could be used at different spatial and temporal scales for monitoring continental regions like the Sahelian belt, namely,

Manuscript received February 17, 2006; revised January 18, 2007. This work was supported in part by the African Monsoon Multidisciplinary Analysis (AMMA) Program and in part by the French ECosphére COntinentale/ Programme National Biosphére Continentale (ECCO/PNBC) Program. Based on a French initiative, AMMA was built by an international scientific group and is currently funded by a large number of agencies, especially from France, U.K., U.S., and Africa. It has been the beneficiary of a major financial contribution from the European Community's Sixth Framework Research Programme. Detailed information on scientific coordination and funding is available on the AMMA International web site http://www.amma-international.org.

F. Baup is with the Centre d'Etudes Spatiales de la Biosphère (Université Paul Sabatier-Centre National de la Recherche Scientifique-Centre National d'Études Spatiales-Institut de Recherche Pour le Développement), 31401 Toulouse cedex 9, France and also with the Antennes, Dispositifs et Matériaux Micro-ondes, Université Paul Sabatier, 31062 Toulouse cedex 9, France.

E. Mougin, P. Hiernaux, A. Lopes, and P. De Rosnay are with the Centre d'Etudes Spatiales de la Biosphère (Université Paul Sabatier-Centre National de la Recherche Scientifique-Centre National d'Études Spatiales-Institut de Recherche Pour le Développement), 31401 Toulouse cedex 9, France.

I. Chênerie is with the Antennes, Dispositifs et Matériaux Micro-ondes, Université Paul Sabatier, 31062 Toulouse cedex 9, France.

Digital Object Identifier 10.1109/TGRS.2007.893824 the Wind Scatterometer (WSC) and the Synthetic Aperture Radar (SAR) [1].

On one hand, owing to its high temporal repetitivity (four to five days in theory) associated to a spatial resolution of about $50 \mathrm{~km}$, the ERS WSC has provided useful data over the Sahel during a ten-year period [2]-[6]. Since 2001, QuickScat scatterometer observations took over from those delivered by ERS [7], although at a higher microwave frequency. Studies of these data have shown that Sahelian surfaces exhibit marked seasonal and interannual signatures [2]. The potential of spaceborne C-band scatterometers for observing semiarid areas originates from their high sensitivity to the drastic changes of surface dielectric properties between the successive dry and wet seasons, including the amount of green vegetation and the top-soil moisture content [4], [8], [9]. Observations made at large incidence angles were found in to be good agreement with vegetation cover, whereas low incidence angle acquisitions were related to the variation of soil-moisture content [5], [9].

On the other hand, the ERS SAR has provided high spatial resolution acquisitions [10], [11] at about $23^{\circ}$ of incidence angle. At such angles, there is a good relationship between the backscattering coefficient and the surface soil moisture (SSM) [1], [11]. However, the low temporal repetitivity (35 days) of SAR observations prevents regular monitoring of the SSM.

With a spatial resolution that ranges between $150 \mathrm{~m}$ and $1 \mathrm{~km}$, associated to a temporal repetitivity of a few days, ENVISAT/ASAR data with two of its ScanSAR modes [Wide Swath (WS) and Global Monitoring (GM)] fill the gap between the high spatial resolution/low temporal repetitivity SARs like the one onboard ERS and the low spatial resolution/high temporal resolution scatterometers like the ones onboard ERS and QuickScat. Furthermore, these ENVISAT ASAR data are consistent with the low- and medium-resolution optical images like those acquired by the National Oceanic and Atmospheric Administration/Advanced Very High Resolution Radiometer, Terra/Moderate Resolution Imaging Spectroradiometer, and Satellite Pour l'Observation de la Terre (SPOT)/Vegetation instruments, allowing a synergetic use of both data sets. However, these new observation modes for SAR data still need to be evaluated prior to their integration into a multispectral framework.

This paper aims to investigate the capabilities of ENVISAT/ ASAR data to characterize and monitor soil surfaces in the Sahelian region. Emphasis is put on coarse- and mediumresolution images which offer a better temporal repetitivity and spatial coverage than the high-resolution ones. The considered period is January 2004-December 2005. This paper is organized as follows: The study site and the associated ground and radar data are described in Section II. Section III presents the 


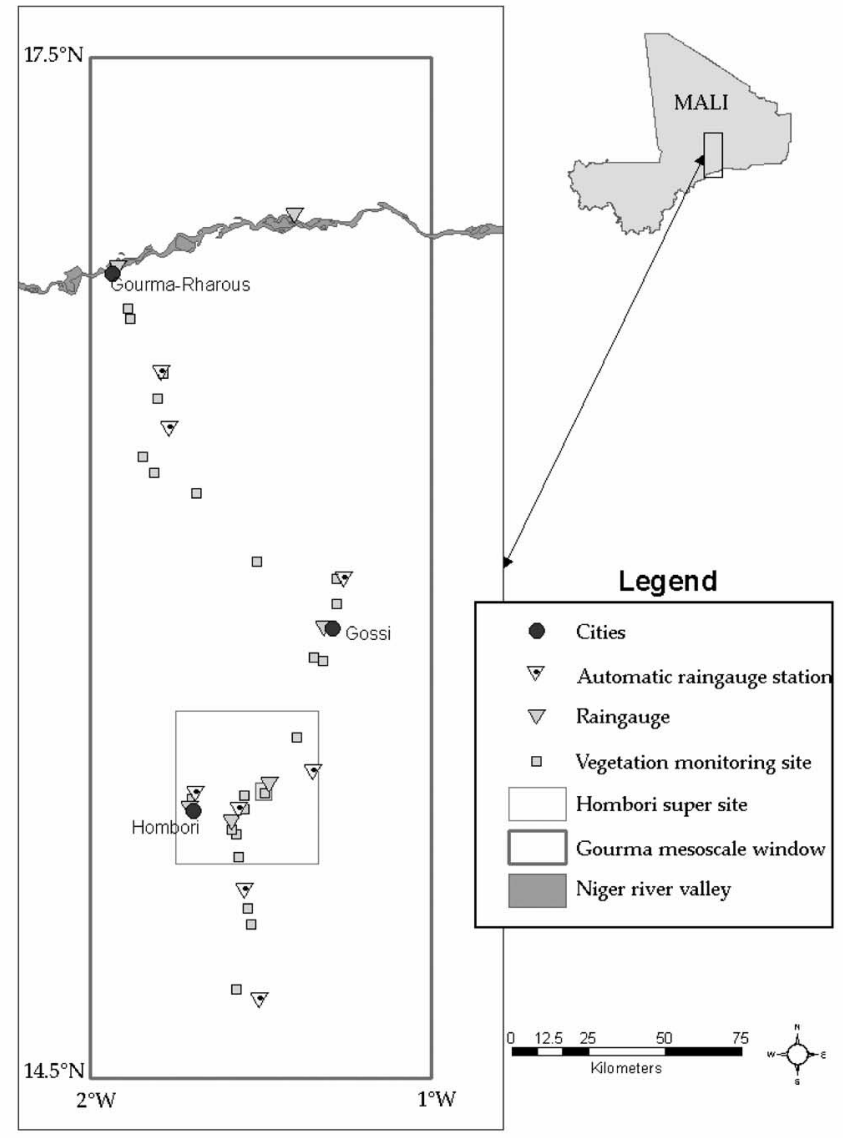

Fig. 1. Gourma window in Mali showing the field site $(\square)$ and raingauge $(\nabla)$ networks.

data analysis and results. The conclusions and perspectives are given in Section IV.

This paper is part of the African Monsoon Multidisciplinary Analysis (AMMA) [12] project whose objectives are to provide a better understanding of the interannual and seasonal variability of the west African monsoon.

\section{Data AND Test Site}

\section{A. Gourma Region}

The study site is located in the Gourma region in Mali between $14.5^{\circ} \mathrm{N}$ and $17.5^{\circ} \mathrm{N}$ and $1^{\circ} \mathrm{W}$ and $2^{\circ} \mathrm{W}$. This region entirely belongs to the Sahel bioclimatic zone and extends to the south of the Niger River between Timbuctu and Gao down to the border with Burkina-Faso (Fig. 1). This is mainly a pastoral region bracketed by the annual 500- and $150-\mathrm{mm}$ isohyets. Rain distribution is strictly monomodal with rainfalls starting in June and ending in September with a peak in August. The rainy season is then followed by a long dry season characterized by the absence of green vegetation apart from some scattered trees and shrubs. Rangeland vegetation is composed of a herbaceous layer dominated by annual species and a sparse woody plant population. Herb growth is strongly influenced by the soilmoisture regime that results from the pattern and magnitude of rainfall events and by and from runoff influenced by topography and soil texture. Annual herbs germinate after the first rains in
TABLE I

Soil ClassificAtion

\begin{tabular}{cl}
\hline \hline Soil Class & Soil Characteristics \\
\hline A & Clayed soils (clay $>35 \%$ ) \\
D & Fixed dunes, sandy soils (sand $>85 \%$ and depth $>1 \mathrm{~m}$ ) \\
E & Sandy sheet (sand $>85 \%$ and depth $<1 \mathrm{~m}$ ) \\
G & Soils covered by gravels \\
H & Flooded Soils \\
L & Loamy soils (loam $>35 \%$ ) \\
R & Rocky soils \\
S & Sandy plain soils (sand $>85 \%$ and depth $>1 \mathrm{~m}$ ) \\
T & Loamy sand soils \\
\hline \hline
\end{tabular}

June or July, and unless the plants wilt before maturity by lack of rain, the senescence matches approximately with the end of the rainy season. The Gourma is part of a large sedimentary basin, and the bedrocks are mainly composed of Precambrian sandstones and schists. In addition to rock outcrops, there are extended erosion surfaces on ferralitic hard pans, alluvial systems, lacustrine depressions, and extended fixed dune systems.

\section{B. Field Data Collection}

Based on visual interpretation of a color composite of Landsat scenes at the scale of 1/200000, Gourma has been stratified into nine types of soil substrate (Hiernaux, unpublished data) listed in Table I. The nine types of soils include rock outcrops (R), soils covered by gravels or iron pan (G), sand dune (D), sandy plain (S), sand sheet (E), loamy sands (T), loamy flats (L), clay plains (A), and flooded depressions (H). At that scale, most of the land units are mosaic of up to four soil types. The relative area, in percent, covered by each component soil type was estimated in number of deciles. For this analysis, each land unit has been characterized by the dominant soil type (equal or more than $40 \%$ of the area) of the mosaic. Within the Gourma window, the dominant soil classes are represented by the sandy soils (D, E, and S), the gravely/rocky soils (G and R), and to a lesser extent by the loamy and clayed soils (L, A, and H). These classes cover 52\%, $29.3 \%$, and $18.7 \%$, respectively.

Twenty-two monitored field sites are located along a north-south transect within a $3^{\circ} \times 1^{\circ}$ window that constitutes the AMMA mesoscale site in Mali (see Fig. 1). The size of the sites is $3 \times 3 \mathrm{~km}^{2}$ except the four sites for which the considered surface is restricted to $1 \times 1 \mathrm{~km}^{2}$ due to the heterogeneity of the soils. These sites are distributed within the nine identified soil classes previously defined. The sites' coordinates and soil class are given in Table II.

The standing mass and green cover of herbaceous, and the crown cover of woody plants were seasonally monitored in the 22 field sites (see [13] for the sampling method). Overall, the woody plant cover is low $(2 \%-6 \%)$ on most sites apart from the three open forest sites $(30 \%-40 \%)$. In addition, the green leaf area index (LAI) was estimated by hemispherical photographs at site \#17 [14]. Automatic measurements of the SSM were also recorded at the site \#17 for which a more 
TABLE II

Localization, Soil Class, ANd Size of the Field Sites

\begin{tabular}{|c|c|c|c|c|}
\hline Site \# & $\begin{array}{c}\text { Latitude } \\
\left({ }^{\circ} \mathrm{N}\right)\end{array}$ & $\begin{array}{c}\text { Longitude } \\
\left({ }^{\circ} \mathrm{W}\right)\end{array}$ & $\begin{array}{c}\text { Soil } \\
\text { Class }\end{array}$ & $\begin{array}{r}\text { Size } \\
\left(\mathrm{km}^{2}\right)\end{array}$ \\
\hline 1 & 16.761 & 1.887 & D & $3 \times 3$ \\
\hline 2 & 16.731 & 1.882 & $\mathrm{~L}$ & $3 \times 3$ \\
\hline 4 & 16.574 & 1.785 & $S$ & $3 \times 3$ \\
\hline 5 & 16.499 & 1.798 & D & $3 \times 3$ \\
\hline 6 & 16.328 & 1.848 & D & $3 \times 3$ \\
\hline 8 & 16.277 & 1.805 & G & $3 \times 3$ \\
\hline 9 & 16.218 & 1.686 & A & $1 \times 1$ \\
\hline 10 & 16.018 & 1.507 & D & $3 \times 3$ \\
\hline 12 & 15.967 & 1.274 & D & $3 \times 3$ \\
\hline 14 & 15.891 & 1.276 & D & $3 \times 3$ \\
\hline 16 & 15.695 & 1.319 & $\mathrm{R}$ & $3 \times 3$ \\
\hline 17 & 15.339 & 1.484 & D & $3 \times 3$ \\
\hline 18 & 15.332 & 1.546 & $\mathrm{~S}$ & $3 \times 3$ \\
\hline 19 & 15.322 & 1.698 & D & $3 \times 3$ \\
\hline 20 & 15.290 & 1.545 & A & $1 \times 1$ \\
\hline 21 & 15.218 & 1.568 & A & $1 \times 1$ \\
\hline 22 & 15.150 & 1.562 & G & $3 \times 3$ \\
\hline 25 & 14.997 & 1.547 & D & $3 \times 3$ \\
\hline 28 & 14.762 & 1.568 & $\mathrm{~T}$ & $3 \times 3$ \\
\hline 30 & 14.948 & 1.523 & D & $3 \times 3$ \\
\hline 31 & 15.230 & 1.583 & D & $1 \times 1$ \\
\hline 40 & 15.502 & 1.397 & $\mathrm{G}$ & $3 \times 3$ \\
\hline
\end{tabular}

detailed analysis is conducted in the last section of this paper. These measurements are performed using a theta probe sensor [15], which was set at 5-cm depth. Due to the homogeneity of this field site, local SSM measurements are assumed to be representative of the entire site.

\section{Description of ENVISAT ASAR Data}

The ENVISAT satellite was launched by the European Space Agency (ESA) on March 1, 2002. Onboard are the different Earth observation instruments, one of which is a radar sensor: ASAR [16]. This instrument is a multimode sensor which operates in the C-band $(5.3 \mathrm{GHz})$ at several polarizations $(\mathrm{HH}, \mathrm{VV}, \mathrm{HV}$, and $\mathrm{VH})$, incidence angles, and spatial/ radiometric resolutions depending on the functioning mode [16], [17]. At this frequency, atmospheric perturbations can be considered negligible except large convective systems [18]. The ASAR instrument may operate as a conventional stripmap SAR (image and wave modes) or as a ScanSAR (GM, WS, and alternating polarization modes) [19], [20]. As there is only one power supply for the ASAR antenna, the five modes are exclusive operations.

The ASAR data are provided by ESA [21], [22]. In this paper, emphasis is put on the two following ScanSAR modes: GM and WS. For these two modes, the incidence angles range between $16^{\circ}$ and $43^{\circ}$ [19], [23]. The temporal repetitivity for the ScanSAR modes over the Gourma window is of about three images per decade (ten days) over the 2004-2005 period. All the images used are level $1 \mathrm{~b}$ products [23].

\section{Data Calibration and Geocoding}

ASAR data are calibrated using Basic ENVISAT SAR Toolbox software provided by ESA [24]. The calibration algorithm can be found in [25]. The geocoding is performed using
TABLE III

SUMMARY OF ASAR AND ERS PERFORMANCES

\begin{tabular}{|c|c|c|c|c|c|}
\hline Parameter & Unit & IM Mode & WS Mode & GM Mode & ERS-1/2 \\
\hline Polarization & & VV or $\mathrm{HH}$ & $\mathrm{VV}$ or $\mathrm{HH}$ & VV or $\mathrm{HH}$ & VV \\
\hline Spatial resolution & $\mathrm{m}$ & $27.5 \times 28.1$ & $149 \times 145$ & $949 \times 977$ & $27.5 \times 28.1$ \\
\hline Radiometric resolution & $\mathrm{dB}$ & 1.54 & 1.45 to 1.72 & 1.35 to 1.44 & 2.07 \\
\hline Radiometric Accuracy $(1 \sigma)$ & $\mathrm{dB}$ & 0.39 to 0.46 & 0.40 to 0.48 & 0.51 to 0.58 & $\mathrm{n} / \mathrm{a}$ \\
\hline Radiometric stability $(1 \sigma)$ & $\mathrm{dB}$ & 0.32 to 0.40 & 0.32 to 0.42 & 0.46 to 0.53 & $0.24 / 0.27$ \\
\hline Noise equivalent $\sigma_{n}^{0}$ & $\mathrm{~dB}$ & -19.6 to -22.1 & -20.9 to -26.2 & -31.5 to -35.0 & -26.2 to -25.2 \\
\hline Effective number of looks & & $\sim 4$ & $\sim 13$ & $\sim 7$ & $\sim 3$ \\
\hline
\end{tabular}

the Interface Definition Language/ENvironment for Visualizing Images (IDL/ENVI) software [26], and the results are assessed by superimposing an ASAR image onto a Landsat Thematic Mapper (30-m pixel spacing). Final precision is estimated to be lower than one pixel.

\section{E. Evaluation of Data Quality}

The general performances of the two concerned ScanSAR modes (GM and WS) and one stripmap mode (IM) are compared to the ERS SAR in Table III [17]. The radiometric resolution determines the ability of a SAR system to distinguish different uniform regions, by assuming negligibly the radar noise from the distributed target. Within a resolution cell, speckle and thermal noise affect the variance of the backscattered power received by the ASAR. The radiometric resolution is given by the confidence interval associated to the measurements (at $1 \sigma, 1.96 \sigma, \ldots$, where $\sigma$ denotes the standard deviation). Similar performances are given for the ASAR WS, GM, and IM modes with radiometric resolutions ranging between 1.6, 1.4, and $1.54 \mathrm{~dB}$ (Table III), respectively, which is a significant improvement when compared to the ERS-1/2 one $(2.07 \mathrm{~dB})$. The radiometric accuracy is the absolute accuracy of the radar cross-sectional measurement of a target imaged by a SAR (i.e., the difference between the actual and measured target radar cross section). The radiometric accuracy does not show significant differences between modes with values of about $0.45 \mathrm{~dB}$ (Table III). The radiometric stability is the standard deviation of the measured radar cross section over time. The performances are similar for the IM and WS modes with values of about $0.35 \mathrm{~dB}$ and reach $0.5 \mathrm{~dB}$ for the $\mathrm{GM}$ mode. The radar noise equivalent $\sigma_{n}^{0}$ measures the thermal noise of the instrument, and it also depends on the satellite product type. The average $\sigma_{n}^{0}$ are $-23.0,-33.2$, and $-20.8 \mathrm{~dB}$ in WS, GM, and IM modes, respectively [19]. The noise equivalent of the GM mode is significantly smaller due to the narrower bandwidths, both in range and azimuth [27], [28]. In contrast, the effective number of looks is only 7 compared to 13 for the WS mode (Table III). The spatial resolutions are about 150 , 1000 , and $30 \mathrm{~m}$ for the WS, GM, and IM modes, respectively.

The backscattering coefficient $\sigma^{0}$ is estimated for each site, by averaging pixel values over a $3 \times 3$ (or $1 \times 1$ ) $\mathrm{km}^{2}$ window in order to reduce radiometric errors due to speckle and neglecting $\sigma_{n}^{0}$. Fig. 2 illustrates the variation of $\sigma^{0}$ and of the associated radiometric resolution for the sandy site \#17, as a function of the size of the sampling window for the two 


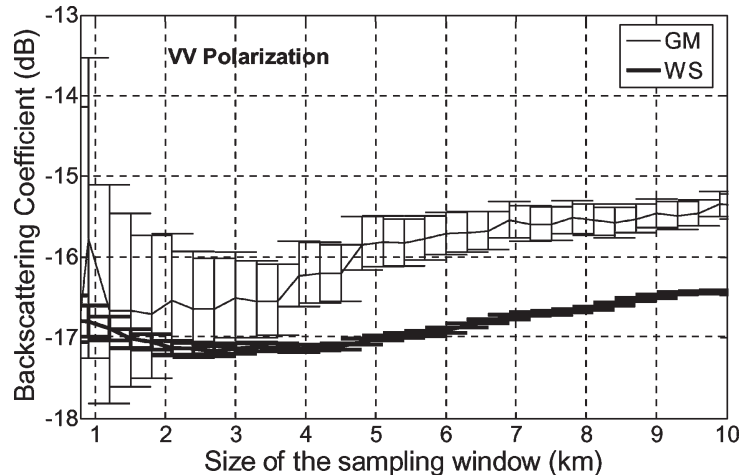

Fig. 2. Variation of the radiometric resolution versus the size of the sampling window for a GM image acquired on February 24, 2004 and a WS image acquired on January 16, 2005 (VV polarization). The angles of incidence are about $31^{\circ}(\mathrm{GM})$ and $42^{\circ}(\mathrm{WS})$, respectively.

ScanSAR modes at VV polarization. The radiometric resolution $R_{\text {rad }}$ for the measured intensity (at $1 \sigma$ ) is estimated as [25]

$$
R_{\mathrm{rad}}=10 \log \left(1 \pm \frac{1}{\sqrt{\mathrm{NL}_{\mathrm{eff}}}}\right)
$$

with

$$
\mathrm{NL}_{\text {eff }}=N_{\text {pixel_az }} \times N_{\text {pixel_ra }} \times \mathrm{NL}_{\mathrm{az}} \times \mathrm{NL}_{\mathrm{ra}} / R
$$

where $\mathrm{NL}_{\text {eff }}, N_{\text {pixel_az }}, N_{\text {pixel_ra }}, \mathrm{NL}_{\mathrm{az}}$, and $\mathrm{NL}_{\mathrm{ra}}$ denote the effective look number, the number of azimuthal pixels, the number of range pixels, the number of azimuthal looks, and the number of range looks, respectively. $R$ is the number of pixels per independent pixel in the data product and can be calculated as follows:

$$
R=\left(\frac{\rho_{\text {az }}}{\Delta_{\text {spa_az }}}\right) \times\left(\frac{\rho_{\text {ground }- \text { ra }}}{\Delta_{\text {spa_ra }}}\right)
$$

where $\rho_{\text {az }}, \rho_{\text {ground-ra }}$, and $\Delta_{\text {spa_az }}, \Delta_{\text {spa_ra }}$ denote the azimuthal spatial resolution (149 and $949 \mathrm{~m}$ for WS and GM, respectively), the ground range spatial resolution (145 and $977 \mathrm{~m}$ ), and the azimuth and ground range pixel spacing (75 and $500 \mathrm{~m}$ ), respectively. Equation (2) gives $R=3.84$ in WS mode and $R=3.70$ in GM mode.

Results show that a $3 \times 3-\mathrm{km}$ window is large enough to obtain a good accuracy in WS mode (Fig. 2). With such a window, the radiometric resolution is about $\pm 0.06 \mathrm{~dB}$ for a mean backscattering coefficient of $-17.1 \mathrm{~dB}$ in WS mode, whereas it amounts to $\pm 0.6 \mathrm{~dB}$ for a mean backscattering coefficient of $-16.5 \mathrm{~dB}$ in GM mode. The weaker performance of the GM mode can be explained by its coarser spatial resolution $(1 \mathrm{~km}$ versus $150 \mathrm{~m})$ and by its lowest effective number of looks (7 versus 13$)$. A $10 \times 10 \mathrm{~km}$ window would be at least required to get performance similar to that of the WS mode. The difference of the means $\sigma^{0}$ observed in the two images is due to the different incidence angles of $31^{\circ}$ for the GM mode and $42^{\circ}$ for the WS modes.

The radiometric stability is estimated for each field site during the dry seasons in 2004 and 2005. During these periods, the surfaces are assumed to be constant, i.e., there is no temporal variation of the dielectric and geometrical properties of the surfaces, which is a reasonable assumption considering the absence of precipitation and the dryness of the vegetation. Overall, the estimated radiometric stability is better in WS mode $(0.32 \mathrm{~dB})$ than in $\mathrm{GM}$ one $(0.55 \mathrm{~dB})$, indicating a good stability of the instrument in WS mode.

For a $3 \times 3 \mathrm{~km}$ window, assuming all errors are independent and summable (stability, accuracy, and resolution), the estimated confidence interval is $\pm 0.58 \mathrm{~dB}$ (at $1 \sigma$ ) in WS mode and $+0.89 /-0.93 \mathrm{~dB}$ (at $1 \sigma$ ) for GM mode.

Fig. 3 illustrates ASAR images of the same area (center: $17.1^{\circ} \mathrm{N}, 1.6^{\circ} \mathrm{W}$ ) acquired in the GM, WS, and IM modes. The selected area is located in the northern part of the mesoscale window across the Niger river valley. The GM, WS, and IM images have been acquired during the dry season on February 24, 4, and 26, 2004, respectively. Among the three images, the GM one looks very noisy and is the most difficult image to interpret, whereas the IM mode displays a lot of details (sand dunes, Niger stream bed and flood plains, ...) which can also be observed on the WS image.

Fig. 4 shows a comparison between an ASAR-WS image acquired at $\mathrm{VV}$ and $\mathrm{HH}$ polarization and the soil map for the Hombori supersite (see Fig. 1 for its location) during the dry period. Several landscape traits are highlighted on the ASARWS image. The most striking feature is the stream network that appears with high backscattering values (clear), particularly at $\mathrm{HH}$ polarization. The stream network is particularly obvious in the top part of the image (north of the site \#17). The clay plain that cuts the west to the east at the latitude of site \#21 also appears very clearly with high values at $\mathrm{HH}$ polarization. The same applies to the narrow valley located immediately to the north of site \#22 and to the valley to the west of site \#31. The high backscattering values observed in the valleys are due either to the dense woody plant population partially foliated at that season or to the soil humidity. The southeast slopes of escarpments such as that of the sandstone plateaus to the west of site \#31 and north of site \#19 exhibit very high backscattering values, especially at VV polarization, while the steepest slopes oriented northwest present null values (black) corresponding to radar shadow. Other rocky soils, with very sparse trees, present a linear pattern of higher values over the schist-dominated erosion surfaces in the north of the image (site \#40), and no distinct pattern over the iron-pan flat dominates in the southern part of the image (site \#22). On schist, the linear pattern follows that of the schist folding. Sandy soils such as in sites \#17, \#18, \#19, and \#31 appear with relative low backscattering values, due to both a small roughness and low dielectric constant at $5.3 \mathrm{GHz}$ [29]. The linear pattern of the large sand-dune systems that are located in between sites \#18 and \#19, for instance, is not visible on the ASAR-WS image neither at VV nor at $\mathrm{HH}$ polarization.

\section{DATA ANALYSIS}

This section aims to analyze the angular, polarization, and temporal ASAR signatures of the 22 field sites in the Gourma window. Emphasis is put on the GM images since the number of available data is much higher for this mode. The period considered is the dry season, that is, from November 2004 to May 2005. During this period, dielectric and geometrical properties of the surfaces can be considered constant, therefore 


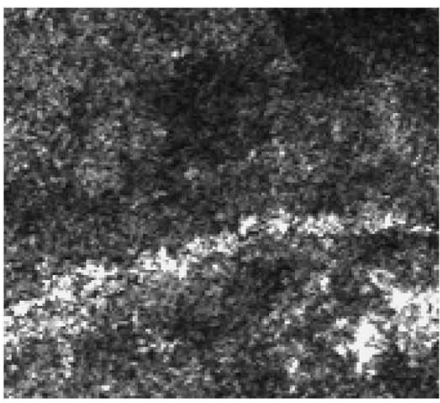

(a)

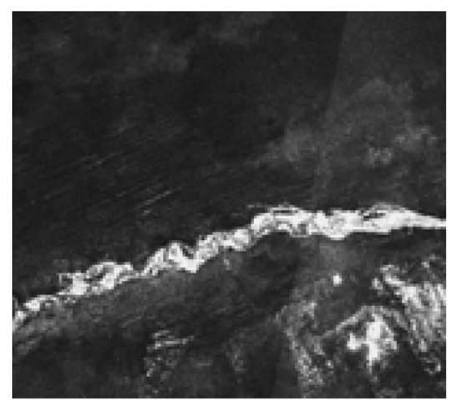

(b)

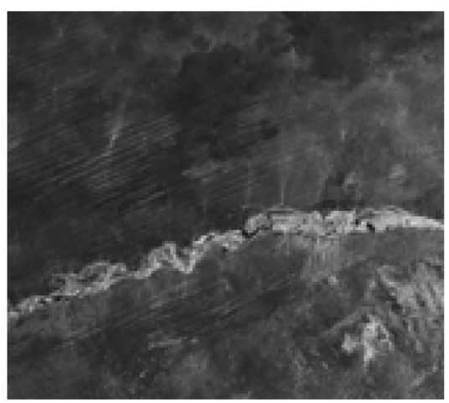

(c)

Fig. 3. Comparison of ASAR images of the same area $\left(17.1^{\circ} \mathrm{N}, 1.6^{\circ} \mathrm{W}\right)$ acquired in three different modes at VV polarization. (a) GM, (b) WS, and (c) IM modes. The size of the images is about $75 \times 85 \mathrm{~km}$. The images were acquired during the dry season on February 24, 4, and 26, 2004 for the GM, WS, and IM modes, respectively.

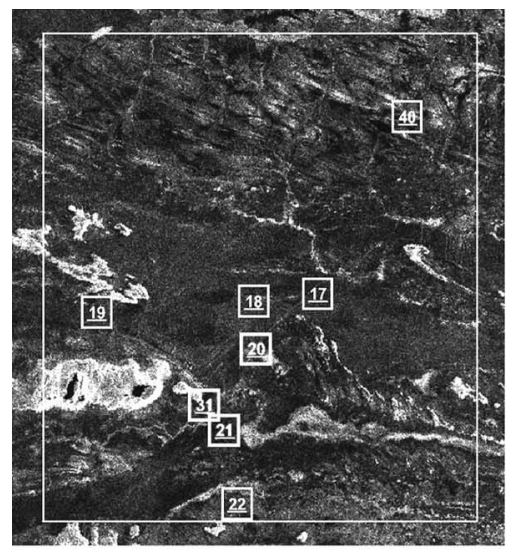

(a)

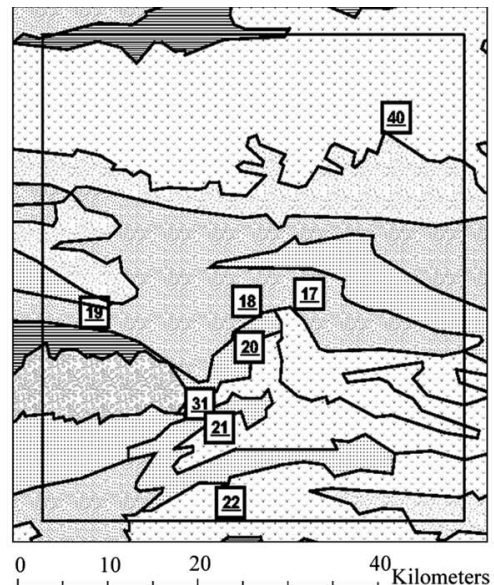

(b)

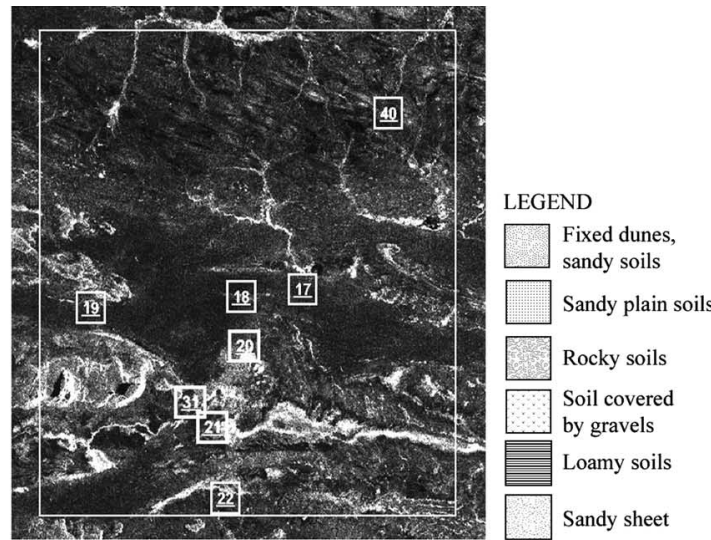

(c)

Fig. 4. (b) Comparison between the soil map and ASAR-WS images acquired at (a) VV polarization on October 10, 2005 and at (c) HH polarization on April 18, 2005.

allowing radar signature comparisons between sites. Indeed, most herbaceous are annuals which wilt from mid-September no matter what the soil-moisture status is and, thus, do not affect the radar response during this period. To the contrary, the heterogeneity, in space and time, of the rainfall events during the rainy season associated to the heterogeneity of the spatial distribution of grass vegetation prevents such comparisons.

\section{A. Angular Signatures}

1) Azimuthal Angle: Azimuthal signatures result from differences between observations made during ascending (as) and descending (de) passes, i.e., at two different azimuthal angles. These differences are expected to be large over arid regions showing well-orientated structures such as sand dunes [7], [30]. The two azimuthal angles of the ASAR instrument are about $100^{\circ}$ and $260^{\circ}$ with reference to the North. On the whole, the azimuthal differences observed are smaller than $1 \mathrm{~dB}$, whatever the polarization, except for the rocky and gravely sites (\#16 and \#40). For these sites, the azimuthal difference is pronounced at $\mathrm{HH}$ polarization and varies between 1.49 and $2.06 \mathrm{~dB}$. Such a difference is illustrated in Fig. 5 for the rocky site \#16. In that particular case, the azimuthal difference could be linked to the linearly orientated pattern of the relief due to differential erosion (a few to 50-m elevation difference) of alternating soft

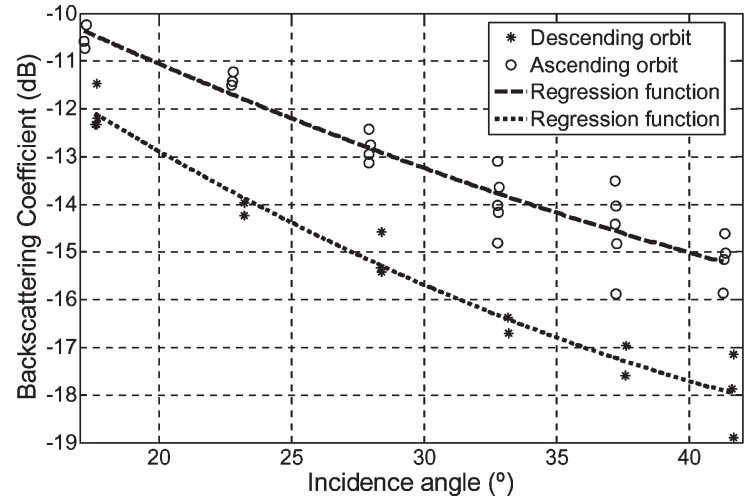

Fig. 5. Angular and azimuthal signatures for a rocky site \#16 at HH polarization for the GM mode (2004-2005 dry season).

schist and hard sandstone layers in high dip folding. It could also be influenced by schistosity that parallels the relief pattern. In contrast, no significant azimuthal signature is found for the sand dune class (D) probably because the fixed dunes are not as sharp, high, and linear as the active dune systems found in the Sahara desert for which the large azimuthal effects are observed.

2) Incidence Angle: During the dry season when both green herbs are absent and the top-soil layer is dry (volumetric 


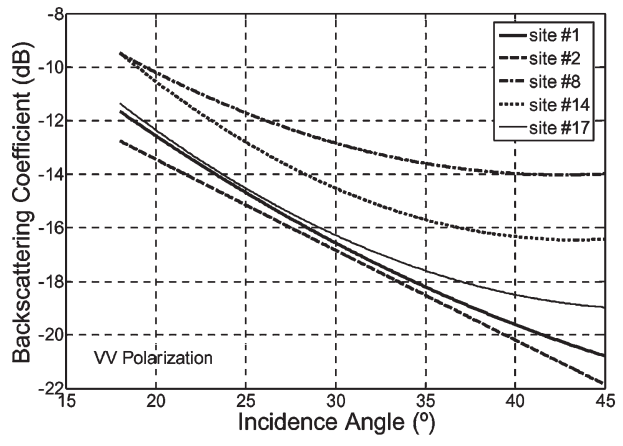

(a)

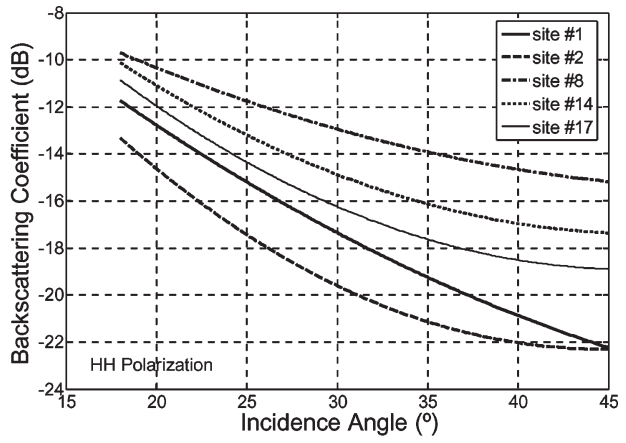

(b)

Fig. 6. Angular signatures of field sites corresponding to different soil classes using GM images at (a) VV and (b) HH polarizations (2004-2005 dry season).

SSM is less than 1\%), the angular signatures mainly depend on topography and soil roughness, and, to a lesser extent, on the characteristics of the woody plant population (density, crown cover, and standing biomass). Fig. 6(a) and (b) illustrates typical angular signatures observed for five representative sites during the dry season at VV and $\mathrm{HH}$ polarization, respectively. Such angular signatures are built by including all available data recorded over the 2004-2005 dry period. The selected sites (\#1, $\# 2$, \#8, \#14, and \#17) belong to the four main soil classes that can be encountered within the Gourma window, namely, fixed dunes (D: sites \#14 and \#17), sandy plain (S: site \#1), soils covered by gravels (G: site \#8), and loamy soils (L: site \#2). The representativeness of the selected sites has been verified by comparing their angular signatures to those of the area of the Gourma map attributed to the corresponding soil classes.

Fig. 6(a) and (b) shows that the angular signatures are strongly dependent on the soil roughness and site geomorphology. A high soil roughness, e.g., on the gravely site \#8, is associated with a high backscattering coefficient and a small slope (about $0.2 \mathrm{~dB} /{ }^{\circ}$ ) at both polarizations. In contrast, the loamy flat site \#2 characterized by a very smooth soil surface exhibits the lowest backscatter associated with a high slope (0.34 and $0.41 \mathrm{~dB} /{ }^{\circ}$ at $\mathrm{VV}$ and $\mathrm{HH}$, respectively). Between these two extremes, the angular signatures of the sandy soils (flat site \#1 and hilly sites \#14 and \#17) are directly dependent on soil roughness and site topography. Overall, a better discrimination between soil classes is obtained at high incidence angles $\left(>35^{\circ}\right)$ in both polarizations.

\section{B. Polarization Signatures}

An important characteristic of the ENVISAT ASAR is its ability to acquire data in the two linear polarizations $\mathrm{HH}$ and VV. However, these observations are made at different dates in GM and WS modes, impeding optimally combined utilization of polarization signatures. Overall, the absolute polarization difference $\left|\sigma_{\mathrm{VV}}^{0}-\sigma_{\mathrm{HH}}^{0}\right|$ rarely exceeds $1 \mathrm{~dB}$ whatever the incidence angle is. There is one exception with the loamy site \#2 and more generally with the soil class (L), characterized by a very flat surface, fine soil texture (loam), and a very sparse shrub layer. In this case, the polarization difference reaches values as high as $3 \mathrm{~dB}$ around $30^{\circ}$ of the incidence angle. The $\mathrm{VV}$ backscattering coefficient is higher or equal to the $\mathrm{HH}$ one except in the forest sites.

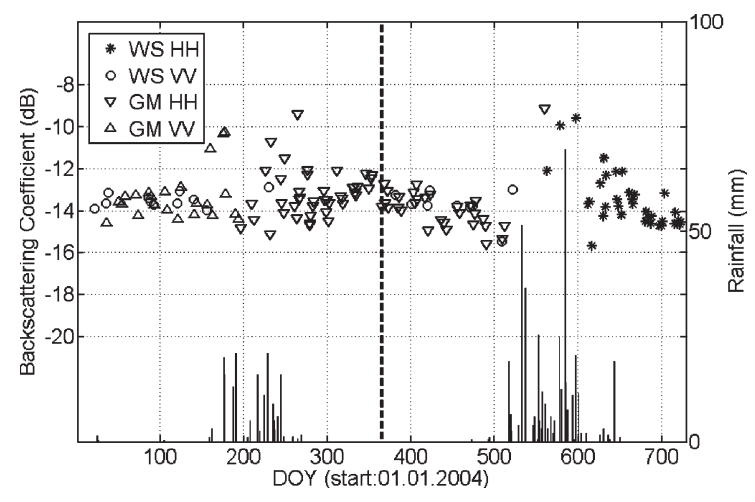

Fig. 7. Temporal variation of the backscattering coefficient for the sandy site \#17 in WS and GM modes at $\mathrm{VV}$ and $\mathrm{HH}$ polarizations after angular normalization at $23^{\circ}$ of incidence angle.

\section{Temporal Signatures}

The measured backscattering coefficient of a given site measured throughout the year is influenced by the temporal variation of soil roughness, SSM, and vegetation cover [31], [32]. As for previous studies based on ERS scatterometer data [5], soil roughness is assumed constant over the year at the considered spatial scale $\left(3 \times 3 \mathrm{~km}^{2}\right)$. Consequently, observed temporal variations of $\sigma^{0}$ are interpreted in terms of SSM and vegetation-cover variations. Prior to this analysis and because ASAR data are acquired at different incidence angles, an angular normalization must be applied to the observations.

1) Incidence Angle Normalization: Following the methodology applied to ERS scatterometer data [2], [33], a polynomial (second order) fit is used to model the variation of the backscattering coefficient (in decibels) versus the incidence angle. For each site, all the data acquired at various incidence angles during the dry period are used to establish the regression function. Then, this function is used to normalize the whole data set, collected during the dry and wet seasons, at an incidence angle of $23^{\circ}$. In order to minimize possible vegetation effect at high incidence angle for the data acquired during the wet season, a new condition is included in data processing. The condition is based on the following rules [31].

1) Only consider the WS and GM data acquired at angles lower than $30^{\circ}$ when green LAI is higher than $0.4 \mathrm{~m}^{2} / \mathrm{m}^{2}$.

2) Consider all WS and GM data acquired at whatever incidence angles when green LAI is lower than $0.4 \mathrm{~m}^{2} / \mathrm{m}^{2}$. 
TABLE IV

ASAR/ENVISAT GM AND WS IMAGE CONFIGURATIONS

\begin{tabular}{|c|c|c|c|c|c|c|c|c|c|c|c|}
\hline \multicolumn{6}{|c|}{ Global Monitoring Mode } & \multicolumn{6}{|c|}{ Wide Swath mode } \\
\hline \multicolumn{3}{|c|}{ HH polarization } & \multicolumn{3}{|c|}{ W polarization } & \multicolumn{3}{|c|}{ HH polarization } & \multicolumn{3}{|c|}{ W polarization } \\
\hline Date & $\begin{array}{l}\text { Incidence } \\
\text { Angle ( }(0)\end{array}$ & $\begin{array}{l}\text { Orbit } \\
\text { path }\end{array}$ & Date & $\begin{array}{l}\text { Incidence } \\
\text { Angle }\left(0^{\circ}\right)\end{array}$ & $\begin{array}{l}\text { Orbit } \\
\text { path }\end{array}$ & Date & $\begin{array}{l}\text { Incidence } \\
\left.\text { Angle ( }{ }^{\circ}\right)\end{array}$ & $\begin{array}{l}\text { Orbit } \\
\text { path }\end{array}$ & Date & $\begin{array}{l}\text { Incidence } \\
\text { Angle }\left(0^{\circ}\right) \\
\end{array}$ & $\begin{array}{l}\text { Orbi } \\
\text { path }\end{array}$ \\
\hline 15/07/2004 & 18,24 & D & 05/02/2004 & 26,27 & A & $16 / 07 / 2005$ & 23,66 & D & $22 / 01 / 2004$ & 18,31 & D \\
\hline 28/07/2004 & 33,66 & D & 20/02/2004 & 38,17 & D & 29/07/2005 & 38,05 & D & $04 / 02 / 2004$ & 33,67 & D \\
\hline $31 / 07 / 2004$ & 23,76 & D & $24 / 02 / 2004$ & 31,14 & A & $01 / 08 / 2005$ & 28,87 & D & $07 / 02 / 2004$ & 23,75 & D \\
\hline 13/08/2004 & 38,1 & D & $27 / 02 / 2004$ & 39,98 & A & 05/08/2005 & 39,96 & A & $26 / 03 / 2004$ & 38,03 & D \\
\hline 19/08/2004 & 18,27 & D & $11 / 03 / 2004$ & 26,26 & A & 14/08/2005 & 42,1 & D & 29/03/2004 & 28,85 & D \\
\hline 20/08/2004 & 39,91 & A & $14 / 03 / 2004$ & 35,82 & A & $17 / 08 / 2005$ & 33,66 & D & $01 / 04 / 2004$ & 18,19 & D \\
\hline 29/08/2004 & 42,12 & D & $27 / 03 / 2004$ & 20,96 & A & 20/08/2005 & 23,71 & D & $30 / 04 / 2004$ & 38,1 & D \\
\hline 01/09/2004 & 33,69 & D & $30 / 03 / 2004$ & 31,24 & A & 02/09/2005 & 38,03 & D & $03 / 05 / 2004$ & 28,95 & D \\
\hline 02/09/2004 & 26,21 & A & $02 / 04 / 2004$ & 40,03 & A & 03/09/2005 & 20,83 & A & 19/05/2004 & 33,68 & D \\
\hline 04/09/2004 & 23,76 & D & $15 / 04 / 2004$ & 26,3 & A & $05 / 09 / 2005$ & 28,84 & D & $04 / 06 / 2004$ & 38,05 & D \\
\hline 05/09/2004 & 35,76 & A & $18 / 04 / 2004$ & 35,84 & A & 06/09/2005 & 31,17 & A & $17 / 08 / 2004$ & 31,14 & A \\
\hline 17/09/2004 & 38,1 & D & $01 / 05 / 2004$ & 20,88 & A & 08/09/2005 & 18,14 & D & $16 / 01 / 2005$ & 42,1 & D \\
\hline 20/09/2004 & 28,9 & D & $04 / 05 / 2004$ & 31,18 & A & 09/09/2005 & 40,04 & A & $04 / 02 / 2005$ & 38,09 & D \\
\hline 21/09/2004 & 31,17 & A & $20 / 05 / 2004$ & 26,28 & A & $18 / 09 / 2005$ & 42,05 & D & $23 / 02 / 2005$ & 33,72 & D \\
\hline $23 / 09 / 2004$ & 18,27 & D & $23 / 05 / 2004$ & 35,81 & A & $21 / 09 / 2005$ & 33,63 & D & $26 / 02 / 2005$ & 23,78 & D \\
\hline $23 / 09 / 2004$ & 18,36 & D & $05 / 06 / 2004$ & 20,94 & A & $22 / 09 / 2005$ & 26,22 & A & $30 / 03 / 2005$ & 33,73 & D \\
\hline $24 / 09 / 2004$ & 40,01 & A & 08/06/2004 & 31,26 & A & $24 / 09 / 2005$ & 23,69 & D & $15 / 04 / 2005$ & 38,06 & D \\
\hline $03 / 10 / 2004$ & 42,13 & D & $11 / 06 / 2004$ & 40,02 & A & $25 / 09 / 2005$ & 35,79 & A & $18 / 04 / 2005$ & 28,88 & D \\
\hline $03 / 10 / 2004$ & 42,14 & D & $24 / 06 / 2004$ & 26,2 & A & $07 / 10 / 2005$ & 38,07 & D & $23 / 05 / 2005$ & 28,91 & D \\
\hline $06 / 10 / 2004$ & 33,67 & D & $26 / 06 / 2004$ & 23,84 & D & $08 / 10 / 2005$ & 20,83 & A & $23 / 05 / 2005$ & 28,91 & D \\
\hline 06/10/2004 & 33,67 & D & $27 / 06 / 2004$ & 35,75 & A & $10 / 10 / 2005$ & 28,87 & D & $05 / 06 / 2005$ & 42,12 & D \\
\hline $03 / 01 / 2005$ & 28,91 & D & & & & $13 / 10 / 2005$ & 18,17 & D & & & \\
\hline $04 / 01 / 2005$ & 31,13 & A & & & & $14 / 10 / 2005$ & 40,01 & A & & & \\
\hline $06 / 01 / 2005$ & 18,29 & D & & & & $23 / 10 / 2005$ & 42,05 & D & & & \\
\hline $07 / 01 / 2005$ & 39,92 & A & & & & $26 / 10 / 2005$ & 33,62 & D & & & \\
\hline 19/01/2005 & 33,71 & D & & & & $27 / 10 / 2005$ & 26,22 & A & & & \\
\hline 20/01/2005 & 26,16 & A & & & & $29 / 10 / 2005$ & 23,67 & D & & & \\
\hline 23/01/2005 & 35,76 & A & & & & $11 / 11 / 2005$ & 38,02 & D & & & \\
\hline 07/02/2005 & 28,99 & D & & & & $12 / 11 / 2005$ & 20,86 & A & & & \\
\hline $08 / 02 / 2005$ & 31,19 & A & & & & $15 / 11 / 2005$ & 31,18 & A & & & \\
\hline $10 / 02 / 2005$ & 18,25 & D & & & & $17 / 11 / 2005$ & 18,15 & D & & & \\
\hline 11/02/2005 & 39,94 & A & & & & $18 / 11 / 2005$ & 39,99 & A & & & \\
\hline 20/02/2005 & 42,17 & D & & & & $27 / 11 / 2005$ & 42,08 & D & & & \\
\hline $24 / 02 / 2005$ & 26,13 & A & & & & $30 / 11 / 2005$ & 33,68 & D & & & \\
\hline 27/02/2005 & 35,71 & A & & & & $01 / 12 / 2005$ & 26,12 & A & & & \\
\hline 12/03/2005 & 20,79 & A & & & & $04 / 12 / 2005$ & 35,73 & A & & & \\
\hline $15 / 03 / 2005$ & 31,17 & A & & & & $16 / 12 / 2005$ & 38,06 & D & & & \\
\hline 18/03/2005 & 40 & A & & & & 17/12/2005 & 20,79 & A & & & \\
\hline 31/03/2005 & 26,19 & A & & & & 19/12/2005 & 28,87 & D & & & \\
\hline $03 / 04 / 2005$ & 35,76 & A & & & & 20/12/2005 & 31,14 & A & & & \\
\hline $16 / 04 / 2005$ & 20,86 & A & & & & $22 / 12 / 2005$ & 18,17 & D & & & \\
\hline 19/04/2005 & 31,25 & A & & & & $23 / 12 / 2005$ & 39,97 & A & & & \\
\hline
\end{tabular}

Anyway, the large observed variations of the backscattering coefficient during the rainy season that result from changes in soil moisture and vegetation parameters do not allow the derivation of a regression function that would be specific for the wet season. Moreover, normalization errors in the dry season are estimated for the two studied modes. The mean errors are equal to \pm 0.25 and to $\pm 0.3 \mathrm{~dB}$ in the WS and GM modes, respectively. Finally, the total errors, including stability, accuracy, resolution, and normalization errors, are equal to \pm 0.63 and $\pm 0.96 \mathrm{~dB}$ in WS and GM modes. Fig. 7 illustrates the temporal variation of the backscattering coefficient after angular normalization for the site \#17 over 2004 and 2005 period, and the configurations of the SAR images used are presented in Table IV. Rainfall events are indicated, showing the succession of dry and wet seasons. In view of the results obtained during the dry seasons for which the backscattering coefficient must be stable, the performance of the simple normalization procedure can be considered satisfactory. Estimated mean standard deviation of the signal during the dry season is equal to $0.5 \mathrm{~dB}$ when considering the two study modes. The same procedure is thus applied to the different sites. On the whole, the maximum range of the annual dynamics of $\sigma^{0}\left(23^{\circ}\right)$ is observed at $\mathrm{HH}$ polarization with values of about $6 \mathrm{~dB}$ for the clayed soil class (A) located in depressions. On the contrary, the smallest of the annual dynamics of about $1 \mathrm{~dB}$ is found over the gravely $(\mathrm{G})$ and rocky $(\mathrm{R})$ soil classes over which herbaceous vegetation remains extremely sparse. Sandy soils exhibit a variety of dynamic ranges from 1 to $6 \mathrm{~dB}$ depending on the rainfall and vegetation cover.
2) Interpretation of $\sigma^{0}\left(23^{\circ}\right)$ Time Series: In this section, emphasis is put on the interpretation of variation over time of the normalized backscattering coefficient $\sigma^{0}\left(23^{\circ}\right)$ observed in the sandy site \#17 (Fig. 7) which belongs to the more frequent soil class (D) within the Gourma region. However, similar temporal profiles are observed over the different sites apart from the gravely and rocky sites which show weak variations throughout the year. For the other sites, the backscatteringcoefficient time series exhibits a marked seasonality associated with the succession of dry and wet seasons. Low $\sigma^{0}\left(23^{\circ}\right)$ values are observed during the dry season from November to May (Day of the Year 305-480) when the soil surface is dry and green vegetation is absent. During this period, the signal is stable with a mean value of about $-13.3 \mathrm{~dB}$ and a standard deviation of $0.55 \mathrm{~dB}$ in GM mode, and $0.32 \mathrm{~dB}$ in WS mode. However, a slight increase is observed from October to December followed by a slight decrease from January to May. The lowest values are observed at the onset of the 2005 wet season, just following the first rains. This decrease of about $1 \mathrm{~dB}$ affects both polarizations and modes and has already been observed at various spatial scales over the Sahel using ERS WSC data [5], [30] and ENVISAT SAR data [10]. Such a decrease in the backscattering is not currently fully understood and might be attributed to a decrease of the surface roughness. However, preliminary observations show no significant variation of the soil roughness. In the wet season of 2005, the soil and the vegetation growth are associated with an increase of the backscattering up to a maximum of about $-9.0 \mathrm{~dB}$ occurring in August. Green LAI for the herbaceous layer reaches maximum values of about 1.8 by the end of August. The peak of the backscatter is followed by a prompt decrease in September or October which corresponds both to the drying of the soil surface and to the senescence of the herbaceous vegetation. The annual amplitude is about 3-4 dB for both seasons in whatever polarization.

The interpretation of these $\sigma^{0}$ temporal series requires a theoretical modeling of the interaction occurring between the incident radar wave and the various components of the illuminated scene. At the considered scale $\left(3 \times 3 \mathrm{~km}^{2}\right)$, the backscattered signal results from different contributions, namely, surface scattering from bare soil and from the soil beneath the vegetation canopy, volume scattering by the vegetation, and interactions between the vegetation components and the soil.

Following the approach proposed in [5], [9], and [34], the total scene backscattering coefficient $\sigma_{\text {total }}^{0}$ is given as the incoherent sum of two components: $\sigma_{\text {baresoil }}^{0}$ for the bare soil surfaces and $\sigma_{\text {canopy }}^{0}$ for the vegetated surfaces, after being linearly weighted by their respective cover fractions

$$
\sigma_{\text {total }}^{0}\left(\theta_{\mathrm{i}}\right)=\left(1-\nu_{\mathrm{c}}\right) \sigma_{\text {bare soil }}^{0}+\nu_{\mathrm{c}} \sigma_{\text {canopy }}^{0}
$$

where $\theta_{\mathrm{i}}$ is the incidence angle and $\nu_{\mathrm{c}}$ is the vegetation-cover fraction provided by the vegetation-growth model.

$\sigma_{\text {canopy }}^{0}$ is calculated using the zero- and first-order solutions of the radiative transfer equation [35]. The vegetation canopy is modeled as a collection of discrete and randomly orientated ellipsoids whose dimensions are chosen to be representative of the main plant species. Vegetation and soil parameters are given 
TABLE $\mathrm{V}$

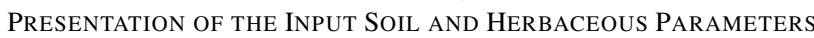
FOR THE RADIATIVE TRANSFER MODEL

\begin{tabular}{ll}
\hline \multicolumn{1}{c}{ Parameters } & Value \\
\hline \hline $\begin{array}{l}\text { Soil parameters } \\
\text { Roughness (cm) }\end{array}$ & 1.4 \\
Volumetric water content (\%) & $\begin{array}{l}\text { Daily output from STEP model } \\
\text { Dielectric constant }\end{array}$ \\
Soil cover fraction, $v_{c}$ & Daily output from STEP model \\
& \\
Herbaceous parameters & \\
Leaf dimensions (cm) & 10 \\
Semi-major axis & 0.3 \\
Semi-minor axis & 0.05 \\
Thickness & \\
Leaf orientation & Uniform distribution \\
$\alpha$ & Erectophile distribution \\
$\beta$ & $45^{\circ}$ \\
$\gamma$ & Ulaby and El Rayes (1987) model \\
Leaf dielectric constant & Daily output from STEP model \\
Leaf density & Daily output from STEP model \\
Grass cover fraction & \\
\hline
\end{tabular}

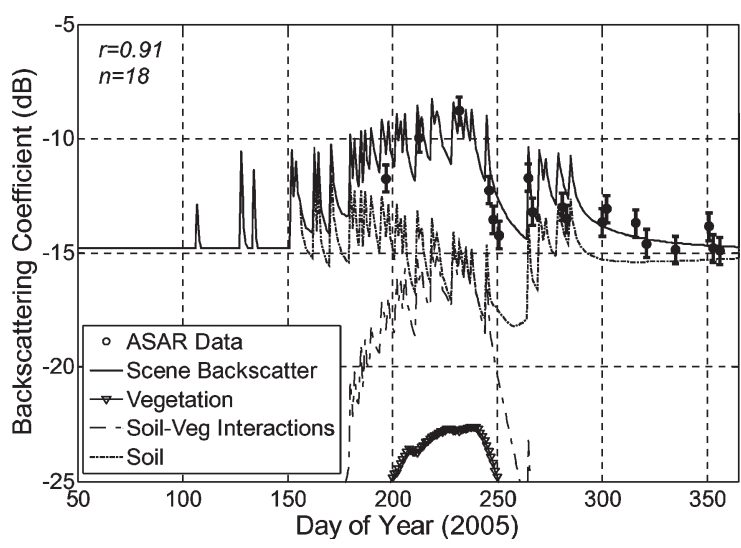

Fig. 8. Simulated scene backscattering coefficient and associated contributions versus time (2005).

in Table V [5], [9]. Besides, the daily variation of vegetation parameters is provided by the vegetation-growth model Sahelian Transpiration and Evaporation Production model (STEP) [33]. In addition, the Oh model [36] is used to simulate the backscattering from the soil, assuming no variation over time of roughness parameters.

The daily variation of the simulated backscattering coefficient is compared to the ASAR data acquired at an incidence angle lower than $30^{\circ}$ (Fig. 8). Overall, there is a good agreement between the model and the data $(r=0.91)$. At $23^{\circ}$ of incidence angle, the volume scattering from the vegetation remains very low even at the peak of biomass and can be considered negligible, which confirms that vegetation effects can be neglected at low incidence angles. Model simulations indicate that the measured backscatter originates from two main contributors, namely, the soil surface and the interaction between the soil and the vegetation. These contributions are mainly driven by SSM which controls the dielectric properties of the upper soil profile which interacts with the incident wave.

3) Relationships Between $\sigma^{0}\left(23^{\circ}\right)$ and SSM: By taking the surface-roughness constant overtime, simulations show that the best correlation between $\sigma^{0}$ and SSM is obtained at $\mathrm{HH}$ polarization due to both larger penetration into the vegetation layer and stronger soil backscatter. These relationships are examined for the site \#17 by plotting the normalized $\sigma^{0}\left(23^{\circ}\right)$ data acquired during the two successive rainy seasons in the GM (2004) and WS (2005) modes against the measured SSM [Fig. 9(a) and (b)]. In order to minimize the vegetation effect when LAI is higher than $0.4 \mathrm{~m}^{2} / \mathrm{m}^{2}$, only the WS and GM data acquired at low incidence angles are considered. All data are used when green LAI is lower than this threshold.

Results show that the normalized backscattering coefficient is correlated to SSM in both ScanSAR modes with the best result obtained in the WS mode $(r=0.81, n=35)$, whereas a weak correlation is found in GM mode $(r=0.55$, $n=7$ ). It is also important to notice that studies dealing with SSM estimation using SAR data in semiarid rangelands generally deal with larger ranges of SSM (up to 30\%). In these studies, only weak relationship appears at low SSM $(<15 \%)$ [37], [38]. Consequently, WS mode appears to be suitable for SSM estimation.

\section{CONCLUSION}

The potential of ENVISAT/ASAR data to characterize and monitor Sahelian soil surfaces is evaluated. Emphasis is put on the analysis of coarse- (GM) and medium-resolution (WS) images delivered by the ScanSAR since they present a good spatial coverage associated to a high temporal repetitivity of a few days (about three to four days in the Sahel). Compared to the GM mode, WS data offer better performance in terms of radiometric, resolution, and radiometric stability. However, in both cases, delivered data at the original resolution $(1000$ and $150 \mathrm{~m})$ must be averaged over a large window in order to reduce speckle effects. The WS mode must be preferred when dealing with local $\left(10 \mathrm{~km}^{2}\right)$ to mesoscale (several $10^{2} \mathrm{~km}^{2}$ ) issues. Besides, the GM mode should be more appropriate for a GM survey with a spatial resolution of at least $10 \times 10 \mathrm{~km}$.

The analysis of the data recorded during the 2004-2005 period over the AMMA Gourma site in Mali shows that the Sahelian surfaces exhibit pronounced angular and temporal signatures that might be used for discriminating soil surface types. In contrast, observed copolarized ratios are small for most of the surfaces observed during the dry season apart from the flat loamy soil class which presents a smooth surface. The joint use of $\mathrm{VV}$ and $\mathrm{HH}$ data can be advantageously used to identify this specific soil type. The potentialities of combined VV and $\mathrm{HH}$ data during the rainy season have not been evaluated due to the absence of simultaneous acquisitions in both polarizations. This point should be addressed in a future work using the ASAR alternating polarization mode, which permits dual observations at different polarizations (HH/VV, $\mathrm{HH} / \mathrm{HV}$, or $\mathrm{VV} / \mathrm{VH})$.

Finally, the dependence of the normalized backscattering coefficient to SSM was sought during the 2004 and 2005 rainy seasons over a sandy site. Results show a significant relationship between $\sigma_{\mathrm{HH}}^{0}\left(23^{\circ}\right)$ and SSM, particularly in the WS mode. These results point out the high potentialities of ENVISAT/ASAR/ScanSAR data for Sahelian surfaces monitoring at global and regional scales. 


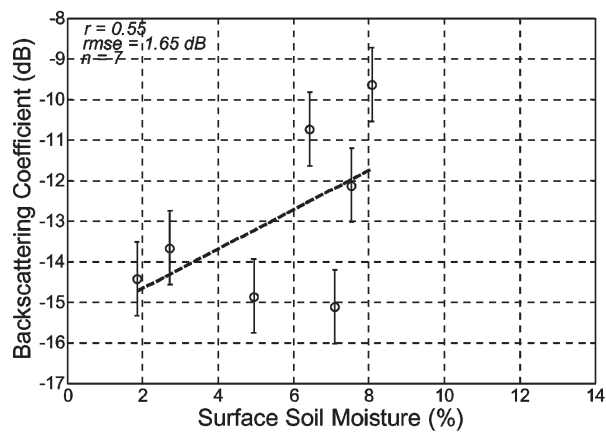

(a)

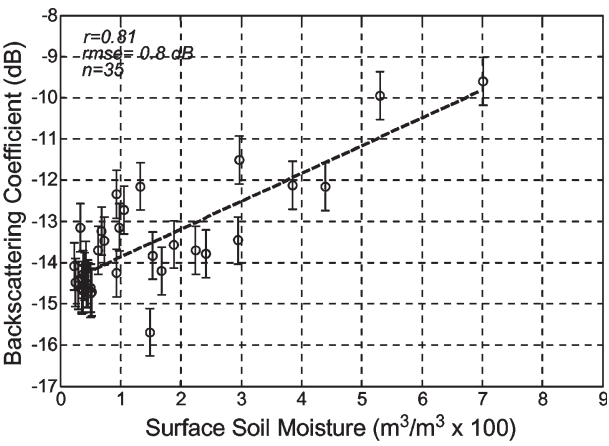

(b)

Fig. 9. Normalized backscattering coefficient versus the SSM content for (a) GM and (b) WS modes at HH polarization for the 2004 and 2005 wet seasons, respectively.

\section{ACKNOWLEDGMENT}

The authors would like to thank ESA for providing the ENVISAT data used in this paper (Project ID 443, E. Mougin). The authors would also like to thank for all the help they got during field measurements, especially from their colleagues and collaborators from the National Institute for Agronomic Research in Mali, the "Institut d'Economie Rurale." The authors would also like to thank $\mathrm{C}$. Couderc for her help in image processing.

\section{REFERENCES}

[1] M. Zribi, S. Le Hegarat-Mascle, C. Ottle, B. Kammoun, and C. Guerin, "Surface soil moisture estimation from the synergistic use of the (multiincidence and multi-resolution) active microwave ERS Wind Scatterometer and SAR data," Remote Sens. Environ., vol. 86, no. 1, pp. 30-41, Jun. 2003.

[2] P. L. Frison and E. Mougin, "Monitoring global vegetation dynamics with ERS-1 Wind Scatterometer," Int. J. Remote Sens., vol. 17, no. 16, pp. 3201-3218, 1996.

[3] K. S. W. Wagner, "Large-scale soil moisture mapping in western Africa using the ERS scatterometer," IEEE Trans. Geosci. Remote Sens., vol. 38, no. 4, pp. 1777-1782, Jul. 2000

[4] I. H. Woodhouse and D. H. Hoekman, "Determining land surface parameters from the ERS-1 Wind Scatterometer," IEEE Trans. Geosci. Remote Sens., vol. 38, no. 1, pp. 126-140, Jan. 2000.

[5] L. Jarlan, E. Mougin, P. L. Frison, P. Mazzega, and P. Hiernaux, "Analysis of ERS Wind Scatterometer time series over Sahel (Mali)," Remote Sens. Environ., vol. 81, no. 2/3, pp. 404-415, Aug. 2002.

[6] L. Jarlan, P. Mazzega, E. Mougin, F. Lavenu, G. Marty, P. L. Frison, and P. Hiernaux, "Mapping of Sahelian vegetation parameters from ERS scatterometer data with an evolution strategies algorithm," Remote Sens. Environ., vol. 87, no. 1, pp. 72-84, Sep. 2003.

[7] H. Stephen and D. G. Long, "Microwave backscattering modeling of Erg surfaces in the Sahara desert," IEEE Trans. Geosci. Remote Sens., vol. 43, no. 2, pp. 238-247, Feb. 2005.

[8] R. D. Magagi and Y. H. Kerr, "Retrieval of soil moisture and vegetation characteristics by use of ERS-1 Wind Scatterometer over arid and semiarid areas," J. Hydrol., vol. 188/189, pp. 361-384, 1997.

[9] P. L. Frison, E. Mougin, and P. Hiernaux, "Observations and interpretation of seasonal ERS-1 Wind Scatterometer data over northern Sahel (Mali)," Remote Sens. Environ., vol. 63, no. 3, pp. 233-242, Mar. 1998.

[10] S. Zine, L. Jarlan, P. L. Frison, P. Hiernaux, and J. P. Rudant, "Land surface parameter monitoring with ERS scatterometer data over the Sahel: A comparison between agro-pastoral and pastoral areas," Remote Sens. Environ., vol. 96, no. 3/4, pp. 438-452, Jun. 2005.

[11] S. Le Hegarat-Mascle, M. Zribi, F. Alem, A. Weisse, and C. Loumagne, "Soil moisture estimation from ERS/SAR data: Toward an operational methodology," IEEE Trans. Geosci. Remote Sens., vol. 40, no. 12, pp. 2647-2658, Dec. 2002.

[12] "La Mousson ouest Africaine et ses composantes," African Monsoon Multidisciplinary Analysis, Feb. 2002. White book. [Online]. Available: http://amma.mediasfrance.org/france/
[13] Y. Tracol, E. Mougin, P. Hiernaux, and L. Jarlan, "Testing a Sahelian grassland functioning model against herbage mass measurements," Ecol. Model., vol. 196, no. 3/4, pp. 437-446, 2006.

[14] M. Weiss, F. Baret, G. J. Smith, I. Jonckheere, and P. Coppin, "Review of methods for in situ leaf area index (LAI) determination. Part II. Estimation of LAI, errors and sampling," Agric. For. Meteorol., vol. 121, no. 1/2, pp. 37-53, Jan. 2004

[15] G. J. Gaskin and J. D. Miller, "Measurement of soil water content using a simplified impedance measuring technique," J. Agric. Eng. Res., vol. 63, no. 2, pp. 153-160, Feb. 1996.

[16] J. Louet. (2001). The Envisat Mission and System, bulletin 106. [Online]. Available: http://www.esa.int/esapub/bulletin/bullet106/bul106_1.pdf

[17] Y. L. Desnos, H. Laur, P. Lim, P. Meisl, and T. Gach, "The ENVISAT-1 Advanced Synthetic Aperture Radar processor and data products," in Proc. IGARSS, Hamburg, Germany, Jul. 1999, pp. 1683-1685.

[18] F. T. Ulaby, A. K. Fung, and R. K. Moore, Microwave and Remote Sensing: Active and Passive, vol. I. Reading, MA: Addison-Wesley, 1981.

[19] R. Torres, C. Buck, J. Guijarro, J. L. Suchail, and A. Schönenberg, "The ENVISAT ASAR instrument verification and characterization," in Proc. CEOS SAR Workshop, Toulouse, France, Oct. 1999, pp. 303-310. ESA-SP450.

[20] M. Zink. (2002, Sep.). "Introduction to the ASAR calibration/validation project," presented at the Envisat Calibration Review, Noordwijk, The Netherlands. [Online]. Available: http://envisat.esa.int/calval/proceedings/ [21] [Online]. Available: http://envisat.esa.int/

[22] EOLI-SA 3.2 User Guide, Nov. 2004. Version 1.6 Draft. [Online]. Available: http://eoli.esa.int/geteolisa/EoliSA-Manual.pdf

[23] European Space Agency, ENVISAT ASAR Product Handbook, Sep. 1, 2004. Issue 1.2.

[24] BEST-Basic ENVISAT SAR Toolbox, User Manual, Version 4.0.2, Mar. 2005. [Online]. Available: http://envisat.esa.int/services/best/ documentation/

[25] H. Laur, P. Bally, P. Meadows, J. Sanchez, B. Schaettler, E. Lopinto, and D. Esteban, Derivation of the Backscattering Coefficient $\sigma_{0}$ in ESA SAR Products. Frascati, Italy: ESA Publication, Sep. 1998. Document No: ES-TN-RS-PM-HL09 17, Issue 2, Rev. 5d.

[26] [Online]. Available: http://www.rsinc.com/

[27] M. Zink, "Early analysis of global monitoring mode," presented at the Envisat Validation Workshop, Frascati, Italy, 2002. [Online]. Available: http://www.envisat.esa.int/workshops/validation_12_02/asar/

[28] J. Closa, "ASAR processing facility status," presented at the Envisat Validation Workshop, Frascati, Italy, 2002. [Online]. Available: http:// www.envisat.esa.int/workshops/validation_12_02/asar/

[29] D. A. Boyarshii, V. V. Tikhonov, and N. Y. Komarova, "Model of dielectric constant of bound water for applications of microwave remote sensing," in Proc. Progress Electromagn. Res., Cambridge, MA, 2002, vol. 35 , pp. 251-269.

[30] P. L. Frison and E. Mougin, "Use of the ERS-1 Wind Scatterometer data over land surfaces," IEEE Trans. Geosci. Remote Sens., vol. 34, no. 2, pp. 550-560, Mar. 1996.

[31] F. T. Ulaby, A. K. Fung, and R. K. Moore, Microwave Remote Sensing: Active and Passive, vol. II. Reading, MA: Addison-Wesley, 1982.

[32] N. Nolah, N. Baghdadi, M. Zribi, A. Bruand, and C. King, "Potential of ASAR/ENVISAT for the characterization of soil surface parameters over bare agricultural fields," Remote Sens. Environ., vol. 96, no. 1, pp. 78-86, May 2005. 
[33] E. Mougin, A. Lopes, P. L. Frison, and C. Proisy, "Preliminary analysis of ERS-1 Wind Scatterometer data over land surfaces," Int. J. Remote Sens., vol. 16, no. 2, pp. 391-398, 1995.

[34] E. Mougin, D. Lo Seen, P. L. Frison, and S. Rambal, "Assessing the complementarity of microwave and optical data for ecosystem modeling in semi-arid regions," in Proc. Satell. and Remote Sens. Symp. Roma, Italy: Europto, Sep. 1994, vol. 2314, p. 48.

[35] M. A. Karam, A. K. Fung, R. H. Lang, and N. S. Chauhan, "A microwave scattering model for layered vegetation," IEEE Trans. Geosci. Remote Sens., vol. 30, no. 4, pp. 767-784, Jul. 1992.

[36] Y. Oh, K. Sarabandi, and F. T. Ulaby, "An empirical model and an inversion technique for radar scattering from bare soil surfaces," IEEE Trans. Geosci. Remote Sens., vol. 30, no. 2, pp. 370-381, Mar. 1992.

[37] M. S. Moran, D. C. Hymer, J. Qi, and E. E. Sano, "Soil moisture evaluation using multi-temporal synthetic aperture radar (SAR) in semiarid rangeland," Agric. For. Meteorol., vol. 105, no. 1-3, pp. 69-80, Nov. 2000.

[38] F. Mattia, G. Satalino, L. Dente, and G. Pasquariello, "Using a priori information to improve soil moisture retrieval from ENVISAT ASAR AP data in semiarid regions," IEEE Trans. Geosci. Remote Sens., vol. 44, no. 4, pp. 900-912, Apr. 2006.

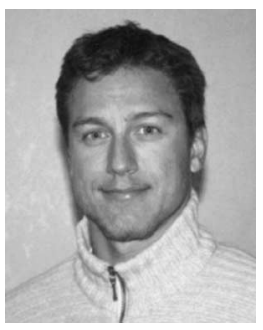

Frédéric Baup was born in Toulouse, France, in 1980. He received the M.S degree in microwave and optical telecommunications from Paul Sabatier University, Toulouse, in 2003. He is currently working toward the Ph.D degree at Antennes, Dispositifs et Matériaux Micro-ondes Laboratory, Toulouse, and at the Centre d'Etudes Spatiales de la Biosphère, Toulouse.

His research interests include microwave remote sensing applied to surfaces and SAR image analysis.

Eric Mougin, photograph and biography not available at the time of publication.

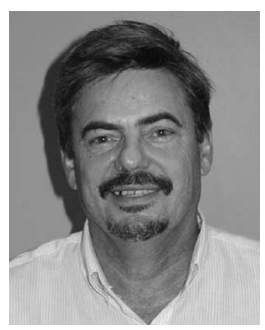

Pierre Hiernaux was an Engineer in agronomy with from the Ecole Nationale Supérieure d'Agriculture de Montpellier (ENSAM) in 1969 with a Ph.D. in vegetation ecology from the University of Montpellier in 1975. He is an expert in ecology and management of tropical rangelands and pastures, and Agricultural System Analyst. He has 30 years of professional experience in tropical Africa and authored or coauthored over 100 publications with an emphasis on plant ecology, range resource survey, applied remote sensing, and bioeconomic modeling of agricultural systems. Since 2005, he has been with Centre d'Etudes Spatiales de la Biosphère, Toulouse, France, under contract with the Université Paul Sabatier, Toulouse, in the framework of the international research project African Monsoon Multidisciplinary Analysis. His research is focused on the characterization of the Earth's surface, including soil, soil humidity and vegetation, their dynamics, and on modeling the underlying processes.
Armand Lopes, photograph and biography not available at the time of publication.

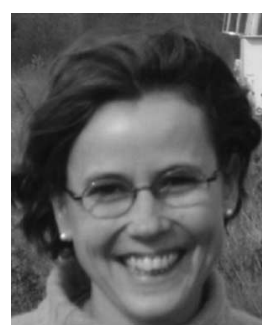

Patricia De Rosnay received the M.S. degree in oceanography, meteorology, and environmental sciences and the Ph.D degree from University Pierre et Marie Curie, Paris 6, Paris, France, in 1994 and 1999, respectively.

She is currently a Research Scientist with the Centre National de Recherches Scientifiques, Centre d'Etudes Spatiales de la Biosphère, Toulouse, France. Her current research interests are focused on passive microwave remote sensing of soil moisture and the study of large-scale land surface processes. She is involved in several land-surface modeling activities such as AMMA Land surface Model Intercomparison Project (ALMIP). In African Monsoon Multidisciplinary Analysis, she coordinates ground-soil-moisture measurements over the Gourma mesoscale site and the validation of the future soil moisture and ocean salinity (SMOS) soil-moisture products. She is involved in the Surface Monitoring of Soil Reservoir EXperiment (SMOSREX) field experiment for soil-moisture remote sensing and complementary scale with the SMOS project.

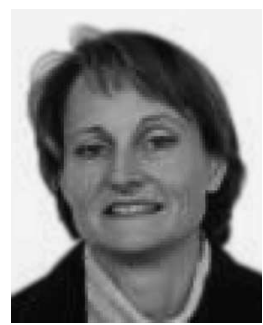

Isabelle Chênerie was born in Albi, France, in August 1959. She received the Ph.D. degree in microwaves and the title of "Habilitation à diriger les recherches" from the University of Toulouse 3 , Toulouse, France, in 1986 and 1996, respectively.

From 1989 to 2001, she was an Associate Professor with Antennes, Dispositifs et Matériaux Microondes Laboratory, Toulouse, and became Professor in 2001. Her current activities of research and education are focused on topics of microwave theory and exploitation of radar data with special emphasis on modeling of coherent scattering from soil and vegetation, and retrieval process of biophysical parameters for radar observations. 